\title{
ZONAL INDICES FOR EUROPE 1780-1995 AND RUNNING CORRELATIONS WITH TEMPERATURE
}

\author{
JUCUNDUS JACOBEIT ${ }^{1}$, PETER JÖNSSON ${ }^{2}$, LARS BÄRRING ${ }^{3}$, \\ CHRISTOPH BECK', MARIE EKSTRÖM ${ }^{3}$ \\ ${ }^{J}$ Geographical Institute, University of Würburg, Germany \\ ${ }^{2}$ Matinö University, Sweden \\ ${ }^{3}$ Deparment of Physical Geography, Lund University, Sweden
}

\begin{abstract}
Zonal circulation indices with monthly and seasonal resolutions are calculated based on gridded monthly mean sea-level pressure (SLP) reconstructed back to 1780 by Jones et al. (1999); an overall zonal index for the whole European arca between $30^{\circ} \mathrm{W}$ and $40^{\circ} \mathrm{E}$, a nomalized index for the North Atlantic Oscillation (NAO), and a similar index for Central Europe. For most of the early time up to the mid-nineteenth century we get preferred negative anomalies in the NAO index for winler and preferred positive ones for summer. The tuming points in cumulative anomalies during the 1850 s for winter and during the 1870 s for summer - indicate a transition period in circulation modes from the "Little Ice Age" to the recent climate in Euroge. Running correlations (time windows of 21 years with time steps of one year) between zonal indices and regional temperature time series from Central England, Stockholm and two Central Eurcpean regions are all indicating major instationarities in these relationships with a particular decline in winter correlations around the turn from the nineteenth to the twentieth centuries. Aspects of different circulation pattems linked with these variabilites are discussed.
\end{abstract}

Key Words: zonal indices; running correlations; temperature; Europe

\section{Introduction}

The atmospheric circulation of the mid latitudes is often described by so-called zonal indices measuring the meridional pressure gradient and hence the strength of the extratropical westerlies at different temporal and spatial scales. Within the North-Atlantic-European region the pressure gradient between the two semi-permanent centres of action, the Iceland Low and the Azores High, is of particular importance. This gradient represents one of the most robust recurrent modes of atmospheric behaviour (Barnston and Livezey, 1987), the North Atlantic Oscillation (Lamb and Peppler, 1987). It accounts for a large proportion of the interannual SLP variability (Rogers, 1990), controls the atmospheric factors leading to changes in the ocean (Dickson et al., 1996), and significantly accounts for hemispheric (Hurrell, 1996) and regional climatic variances (Hurrell, 1995; Hurrell and van Loon, 1997). Zonal indices, however, may also be defined for other regions in Europe (e.g. Jönsson and Bärring, 1994; Jacobeit et al., 1998) or for greater longitudinal sections comprising both the North Atlantic and the European area (Steinrücke, 1999). In any case, particular modes of zonal indices are indicators of specific circulation and climatic modes: In general terms, a large latindinal 
pressure difference (high zonality with higher pressure situated in the south) means that great parts of Europe are affected by a vigorous flow of winds from the westerly sector accompanied by high cyclonic activity and a maritime regime over the northern half of Europe. Low zonality, on the other hand, is linked to a small latitudinal pressure difference. If this gradient is reversed - for example higher pressure over Iceland than over the Azores (see Moses et al., 1987) - we get a meridional or even an easterly flow pattern with strong blocking of the westerlies and large latitudinal excursions of subtropical and polar air masses. Thus, weakened or absent westerly flow over Europe is typical for the low zonality mode representing a continental regime over the northern half of Europe.

Thus, the intensity of the westerlies is a major indicator of the atmospheric circulation and plays a key-role for the climate of Europe. To put the present climatic situation into a long-term perspective it is therefore of great importance to obtain reliable time series as long as possible. Investigations further back in time, before the end of the nineteenth century, have to be concentrated to areas that contain an adequate coverage of stations with long records of barometric pressure. Europe is favoured in that respect, since a rather dense distribution of meteorological stations already existed during the nineteenth century. This makes it feasible to reconstruct a grid point pressure data set for a time period longer than two hundred years covering Europe and the eastern part of the North Atlantic Ocean (Jones et al., 1999). From these gridded data it is possible to calculate monthly zonal indices for Europe from A.D. 1780 to get information about the atmospheric circulation for a period well extending into the "Little Ice Age" lasting from the $1560 \mathrm{~s}$ to the $1850 \mathrm{~s}$ (Flohn, 1993). Thus, the study period since 1780 goes back to times without particular anthropogenic forcing of the climate system and includes the transition from the "Little Ice Age" to subsequently warmer conditions. Time series of the zonal indices should indicate some circulation changes in this climatic transition period.

In the second part of this paper, relationships between the zonal indices and long European temperature time series will be investigated. For the recent century such relationships have been established in various studies, for instance by Malberg and Bökens (1997) concerning positive links between the NAO and Berlin winter temperatures, or by Jönsson and Bärring (1994) showing that the pressure difference between latitudes $45^{\circ} \mathrm{N}$ and $65^{\circ} \mathrm{N}$ has a strong average correlation with southern Scandinavian temperatures in winter $(r=+0.7)$ and - with opposite sign - in summer $(r=-0.6)$. As an important indication, however, the latter study using running correlations also revealed non-stationary features of these long-term average correlations. Similarly, Rogers (1985) concludes that the association between indices of the European westerly wind strength and the mean winter temperatures in southern Norway is not strictly consistent over time. These phenomena might be linked to varying air mass characteristics (Corti et al., 1999) or to frequency changes among different circulation patterns associated with a particular mode of a zonal circulation index. The gridded SLP time series back 
to 1780 (Jones et al., 1999) make it possible to calculate running correlations between zonal circulation indices and long European temperature time series over roughly 200 years and to investigate the consistency of these well-known circulation-climate relationships over this extended period of time. Thus, we will be able to infer whether commonly used associations between zonal index modes and European temperatures are valid beyond the frame of our recent century or, in contrast, are non-stationary and thus reflect conditions of particular sub-periods.

\section{Data}

The monthly mean grid point data of sea-level pressure reconstructed by Jones et al. (1999) back to 1780 for the North-Atlantic-European region are based on homogenized long-term pressure time series from stations with the oldest instrumental records in Europe. The reconstruction is based exclusively on series of measured pressure. The data base starts in 1780 with 10 continuous series, including Lund (Bärring et al., 1999) and Barcelona (Rodriguez et al., submitted). In the 1820s the network is increased to 20 stations, including the Reykjavik area and Gibraltar (Jones et al., 1997), and finally it reaches a set of 51 stations at the middle of the nineteenth century.

The historical SLP data were reconstructed on a $5^{\circ}$ latitude by $10^{\circ}$ longitude grid from 35 to $70^{\circ} \mathrm{N}$ and from $30^{\circ} \mathrm{W}$ to $40^{\circ} \mathrm{E}$ based on EOF-regression models calibrated over the period 1936-1995 and verified for the period 1881-1935. Explained variances reach above $90 \%$ around the central grid points, but decrease towards the periphery, especially for the earliest period with few station pressure series. Generally, explained variances are higher for the winter months than during summer, and this is also true for peripherical regions since the estimation of grid point values further away from available station data is favoured by the more structured large-scale circulation during the winter season (Jones et al., 1999). This reconstruction provides an appropriate data base to calculate some atmospheric circulation indices (see section 3).

Temperature data for northern, western and central Europe were preferably taken in an aggregated manner, only the northernmost part is represented by an individual station, the Stockholm record (Moberg and Bergström, 1997). For western Europe the well-known Central England Temperature time series is used (Manley, 1974; Parker et al., 1992), and for Central Europe two (out of eight) thermal regions have been selected from Beck (2000) each comprising several stations out of 72 temperature time series which were drawn from various sources (World Climate Disc, 1992; Schönwiese and Rapp, 1997; several German Archives). Details about the stations are included in Beck (2000) as well as results of Alexandersson-tests for homogeneity and corrections of identified inhomogeneities. Thermal regions finally have been determined by applying clustering techniques to the matrix of pairwise correlations (Beck, 2000). The two selected regions in this context cover 
parts of southwestern and northeastern Central Europe, respectively, being represented by the following stations:

Central European Region SW (centered around $49.5^{\circ} \mathrm{N}, 8^{\circ} \mathrm{E}$ ):

Aachen, Augsburg, Bamberg, Chalons, Karlsruhe, Langen, Lille, München, Strasbourg, Stuttgart, Trier, Uccle, Würzburg.

Central European Region NE (centered around $54^{\circ} \mathrm{N}, 16^{\circ} \mathrm{E}$ ):

Copenhagen, Elblag, Gdansk, Kaliningrad, Koszalin, Rostock, Szczecin, Stralsund, Sylt, Warszawa.

Thermal indices for these regions are defined by averaging the monthly normalized temperature series from the corresponding stations, respectively.

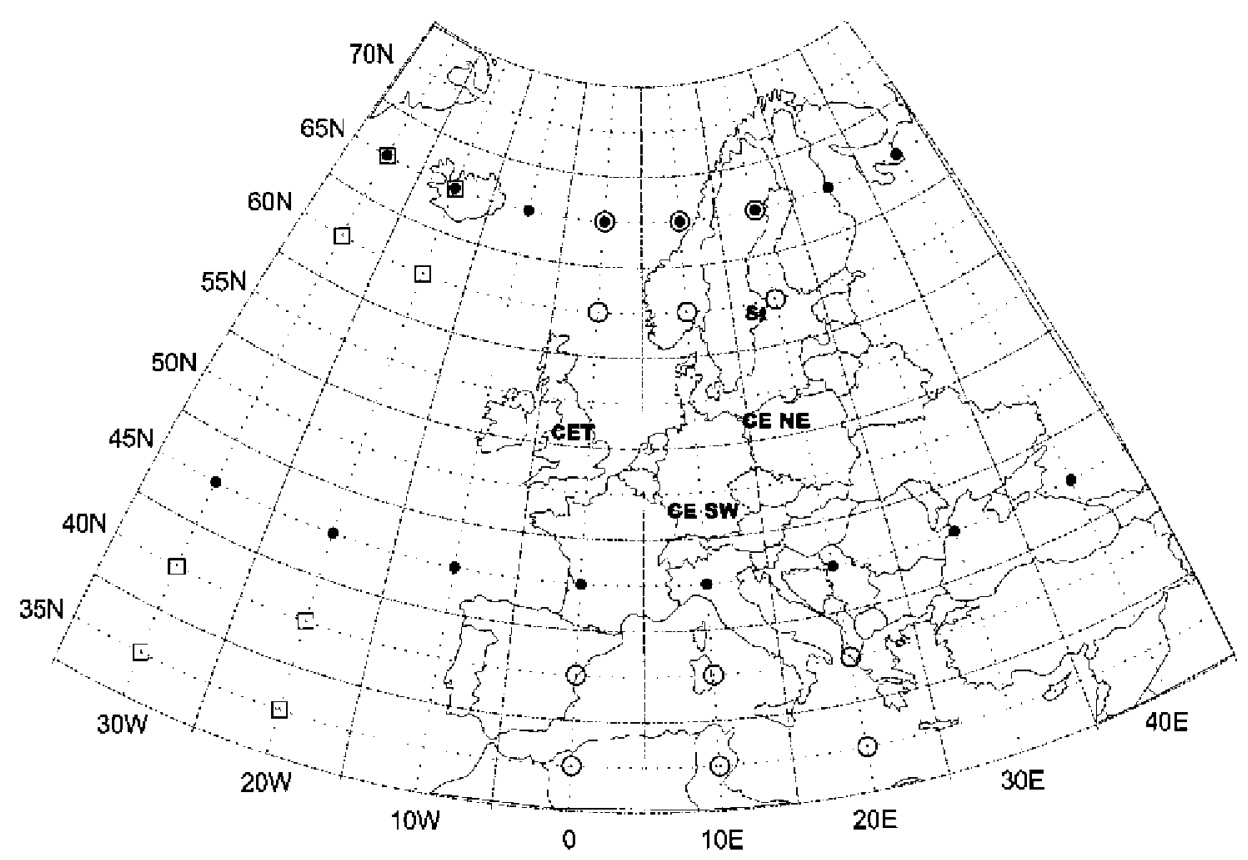

Figure 1. Geographical extension of the historical monthly mean sea-level pressure grid of Jones et al. (1999). Dotted lines show the geographical coordinate system and the grid boxes are indicated as solid lines. Grid boxes used for calculating the various zonal indices are marked as follows: dots - the overall Zonal Index (ZI); open squares - the North Atlantic Oscillation Index (NAOI); open circles - the Central European Zonal Index (CEZI).

Approximate locations of the regional temperature data are indicated with the following abbreviations: CET - Central England temperature;

ST - Stockholm temperature;

CENE - temperature of Central European Region NE;

CESW - temperature of Central European Region SW. 


\section{Methods}

A simple index method of quantifying the strength of the mid-latitude westerlies is to calculate monthly values of the pressure difference between two latitudinal bands and hereby obtaining an overall zonal index for the whole longitudinal area under consideration. High values of this zonal index correspond to a vigorous westerly flow advecting maritime air masses over widespread regions of Europe whereas low zonal index values coincide with a less maritime climate. Using the historical SLP grid from Jones et al. (1999) we get an overall zonal index ZI for the North-Atlantic-European region $\left(30^{\circ} \mathrm{W}\right.$ to $\left.40^{\circ} \mathrm{E}\right)$; calculating $\mathrm{ZI}$ as the pressure difference (hPa) between the latitudes $45^{\circ} \mathrm{N}$ and $65^{\circ} \mathrm{N}$ (see Fig. 1) implies that conditions around the main branch of the westerlies will be considered in particular.

Since the whole North-Atlantic-European area includes significant geographical variations with respect to land-sea distribution and to the important centres of circulation it is necessary to consider regional indices, too. First of all, an index approximating the North Atlantic Oscillation (NAOI) is important. Apart from classical approaches to define a difference between normalized station pressure time series in appropriate locations - e.g. Ponta Delgada/Akureyri (Rogers, 1984), Lisbon/Stykkisholmur (Hurrell, 1995) or Gibraltar/Reykjavik (Jones et al., 1997) there are several approaches based on SLP grid point values: e.g. by determining the moving pressure maxima and minima (Mächel et al., 1998) or by calculating the first grid-based principal component representing the NAO (Wanner et al., 2000). Here we use fixed grid point averages of normalized SLP (see Fig. 1) to remove random variations that would occur within single grid point series. Thus, the NAOI results from differences of normalized SLP averaged over the 4 grid points $35^{\circ} \mathrm{N} / 30^{\circ} \mathrm{W}, 35^{\circ} \mathrm{N} / 20^{\circ} \mathrm{W}, 40^{\circ} \mathrm{N} / 30^{\circ} \mathrm{W}, 40^{\circ} \mathrm{N} / 20^{\circ} \mathrm{W}$ and $60^{\circ} \mathrm{N} / 30^{\circ} \mathrm{W}$, $60^{\circ} \mathrm{N} / 20^{\circ} \mathrm{W}, 65^{\circ} \mathrm{N} / 30^{\circ} \mathrm{W}, 65^{\circ} \mathrm{N} / 20^{\circ} \mathrm{W}$, respectively,

Certainly, the North Atlantic Oscillation represents the major mechanism governing the large-scale circulation variability in Europe (especially in winter), but its area of determination covers the peripherical regions of the historical SLP grid where the reconstruction quality is lower than in the central European region, especially for the first decades before nearby station pressure time series become available (Jones et al., 1999). Therefore, another zonal index has been defined (see Fig. 1) as a specific indicator of the conditions above continental Europe, the region of highest quality in SLP reconstruction. Again fixed grid point averages of normalized SLP are used for this Central European Zonal Index (CEZI) related to the same latitudinal bands as for NAOI (i.e. $35^{\circ} \mathrm{N}-40^{\circ} \mathrm{N}$ and $60^{\circ} \mathrm{N}-65^{\circ} \mathrm{N}$ ) but for the longitudinal section from $0^{\circ}$ to $20^{\circ} \mathrm{E}$.

Concerning correlations between these circulation indices and the four selected temperature time series (Central England, Stockholm, southwestern and northeastern Central Europe) we focus on the consistency of these relationships during the period 1780-1995. We have used the non-parametric Spearman rank correlation 
coefficient to counteract incidental deviations from the normal distribution. Correlations have been calculated for running time windows of 21 years with time steps of one year giving time series of 196 correlation coefficients for each case of circulation-temperature relationship. In addition to time series with seasonal resolution (aggregations into the meteorological seasons: DJF, MAM, JJA, SON), running correlations on a monthly basis are calculated for each season comprising samples of 63 months from the corresponding 21 seasons with time steps, in this case, of 1 month resulting in time series of 586 correlation coefficients for each case of circulation-temperature relationship.

\section{Results}

\subsection{ZONAL INDICES}

Fig. 2 shows the general structure of variation of the overall zonal index (ZI) for the period 1780-1995 for all months of the year. Since this index is defined by latitudinal pressure differences in absolute terms (hPa), seasonal contrasts are distinctly identified: higher values during the cold season, lower ones within the warmer period with regular minima centered around May when the overall pressure gradient is weak over Europe. Since the 1960 s, however, a certain tendency for regular inclusion of early summer into the period of lowest $\mathrm{ZI}$ values seems to be indicated. The consistency during summer (July and August) is striking as well as the pronounced decadal-scale variability in January after the $1850 \mathrm{~s}$ : from a maximum in the late 1850 s there is a decrease to a minimum about 1880 and an increase to a second maximum in the $1910 \mathrm{~s}$, whereafter there is a decrease until the 1940s and an increase again from the 1960s onwards.

The regional indices, NAOI and CEZI, are shown in Fig. 3 as explicit values with seasonal resolution. In addition to seasonal anomalies and smoothed time series, the normalized cumulative anomalies are included in Fig. 3 calculated as the continuous sum of successive seasonal anomalies. Thus, sustainably declining/rising values in cumulative anomalies indicate the prevalence of negative/ positive seasonal anomalies, and major turning points in cumulative anomalies indicate transitions between periods predominated by contrasting seasonal anomalies. Therefore cumulative anomalies reveal decadal and interdecadal variations particularly clear-cut as shown, for example, by Mächel et al. (1998) analyzing circulation time series since 1881 .

The time series in Fig. 3 extended back to 1780 reveal marked differences between the periods before and after the mid-nineteenth century with some particular contrasts between the seasons: thus, NAOI shows a period until the 1850 s with accumulating negative anomalies in winter whereas in summer positive anomalies are prevailing until the $1870 \mathrm{~s}$. This is in contrast to the most recent evolution of the last few decades with positive anomalies prevailing during winter and negative 


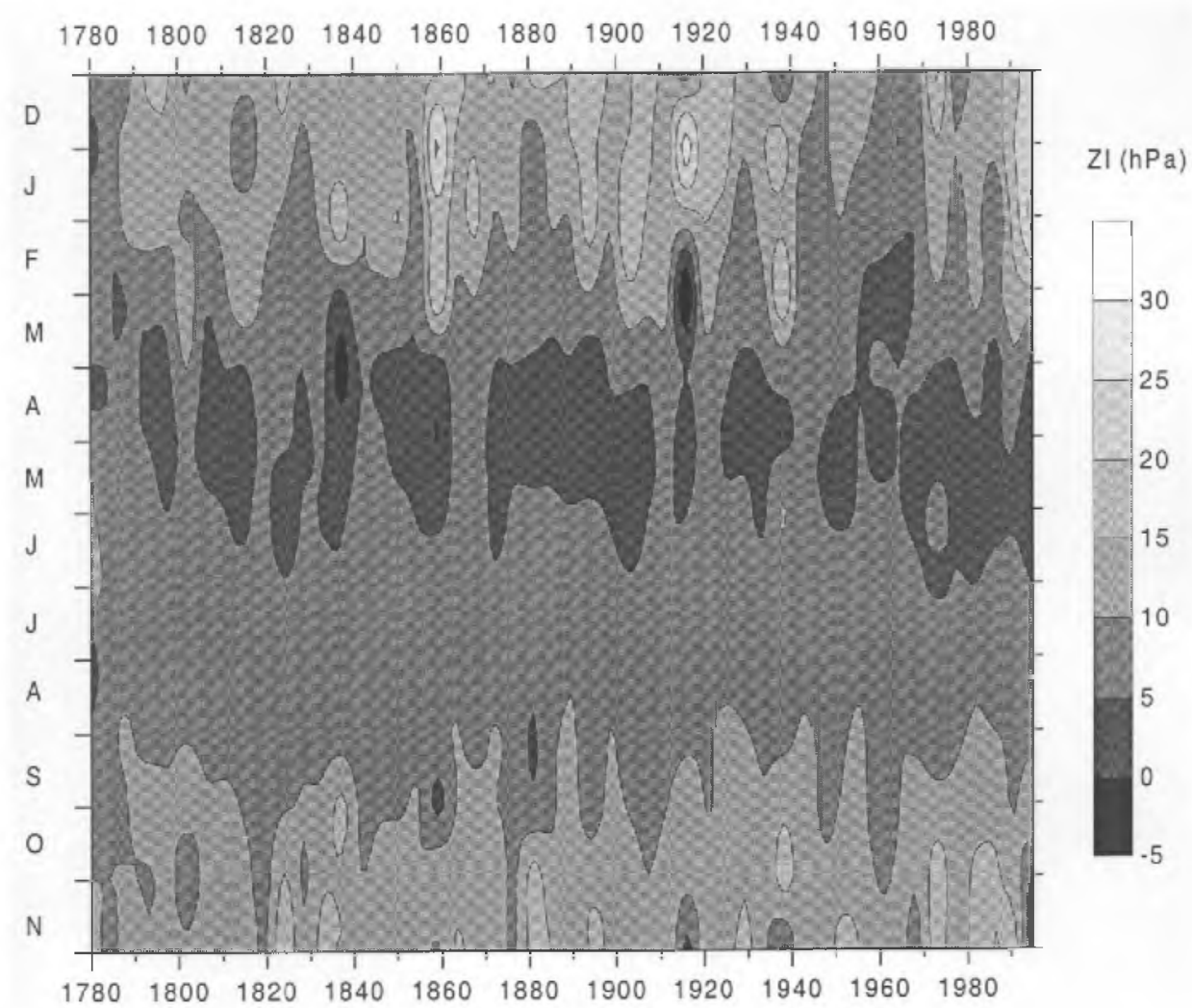

Figure 2. Isopleth diagram showing the cvolution over time of the annual course of the overall zonal index (ZI). The contours are smoothed to show decadal seale variations.

ones during summer. Remarkably, CEZI does not reproduce the dominating low values during winter for the early period mentioned above, although the temperatures for Central Europe indicate a significantly more continental climate for this period, i.e. lower winter and higher summer temperatures than during the recent century (Jacobeit et al., 1998). This might be a general indication of instationarities in circulation-temperature relationships that will be discussed in the following chapter.

Further differences between CEZI and NAOI are manifested by an earlier turning point of cumulative anomalies within the twentieth century indicating the transition from prevailing positive to negative anomalies in winter, and by the absence of a period with cumulating negative anomalies in summer around the turn from the nineteenth to the twentieth centuries. This points to the fact that each NAO mode is linked to a variety of different circulation patterns over Europe implying a complex relationship with temperature even during winter time. 
North Atlantic Oscillation Index for Winter 1780-1995
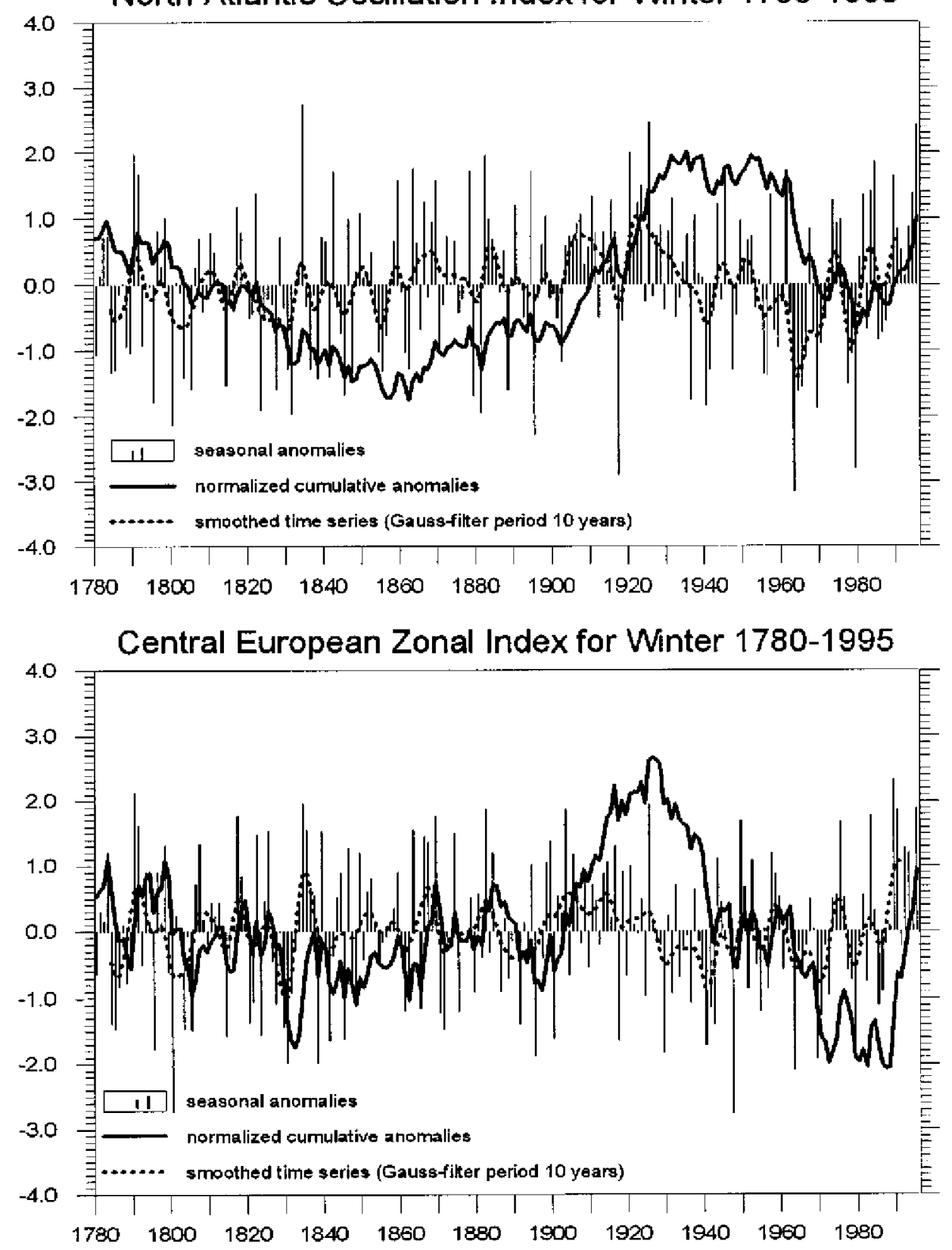

Figure 3. North Atlantic Oscillation Index (NAOI) and Central European Zonal Index (CEZI) derived from gridded North-Atlantic-European sea-level pressure for the meteorological seasons 1780-1995. 
North Atlantic Oscillation Index for Summer 1780-1995

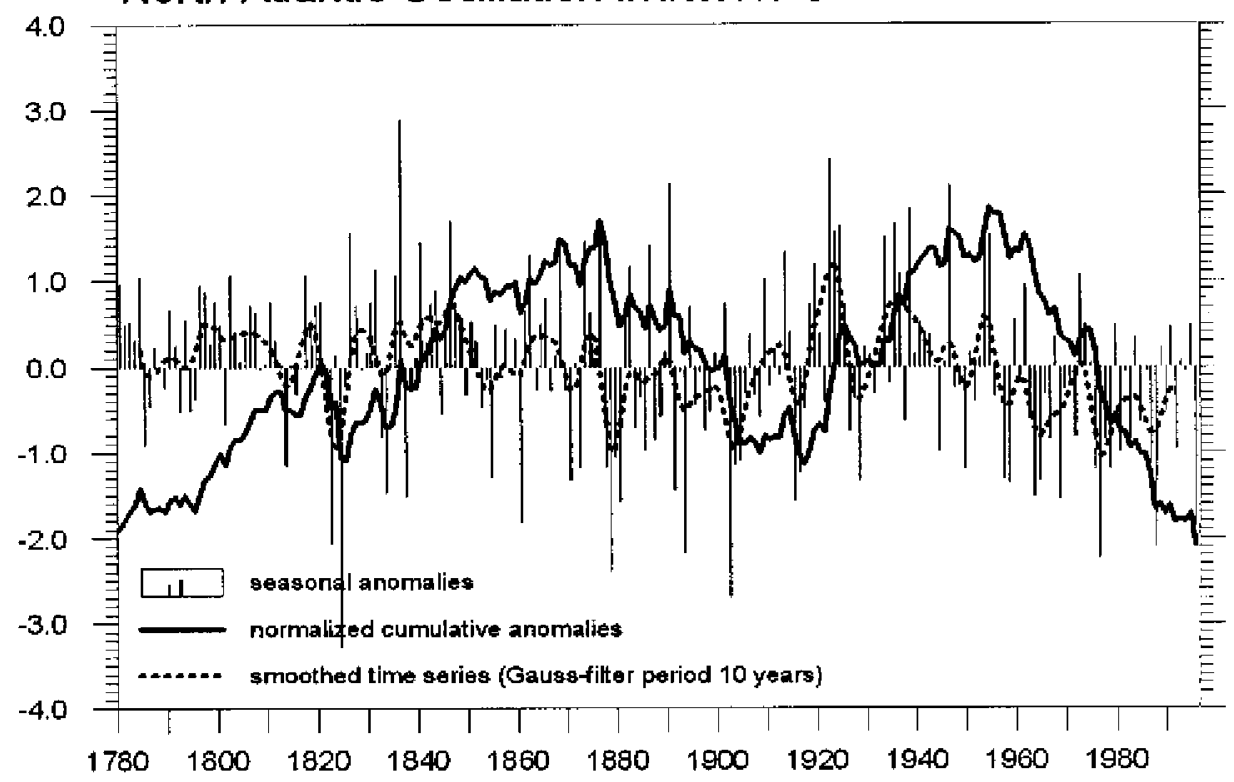

Central European Zonal Index for Summer 1780-1995

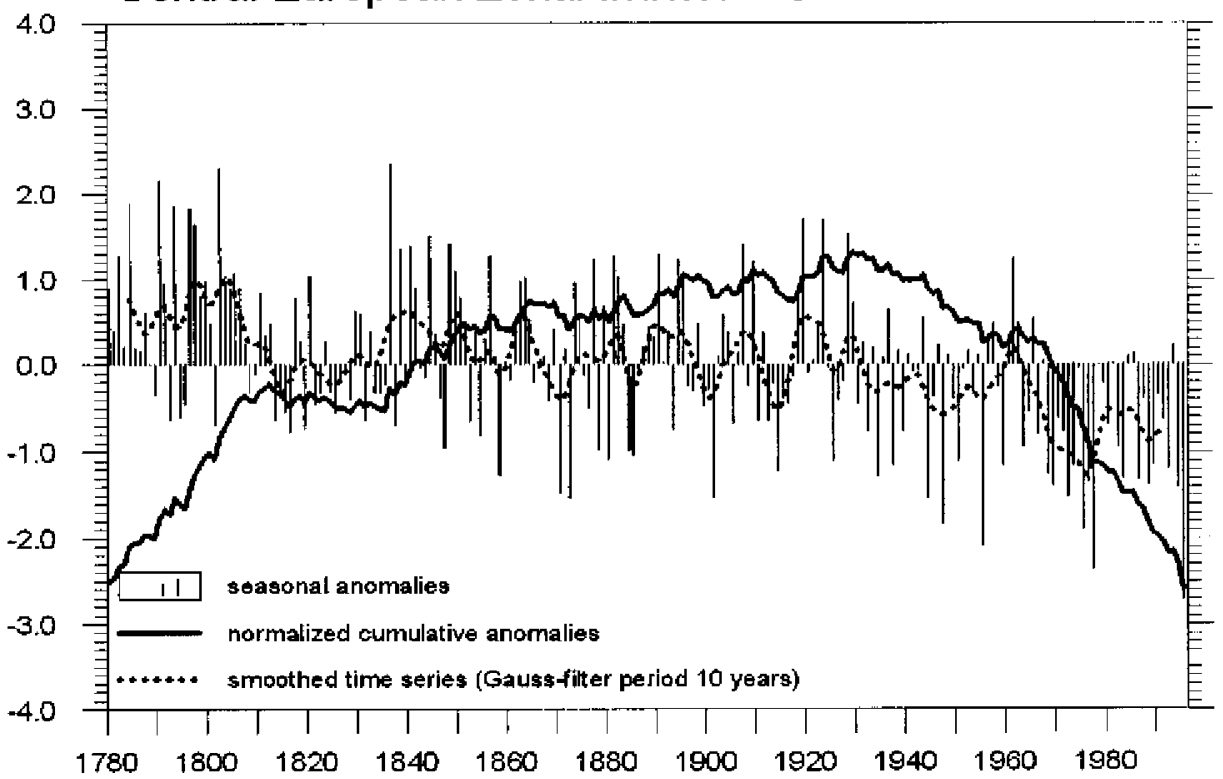

Figure 3. (Continued) 


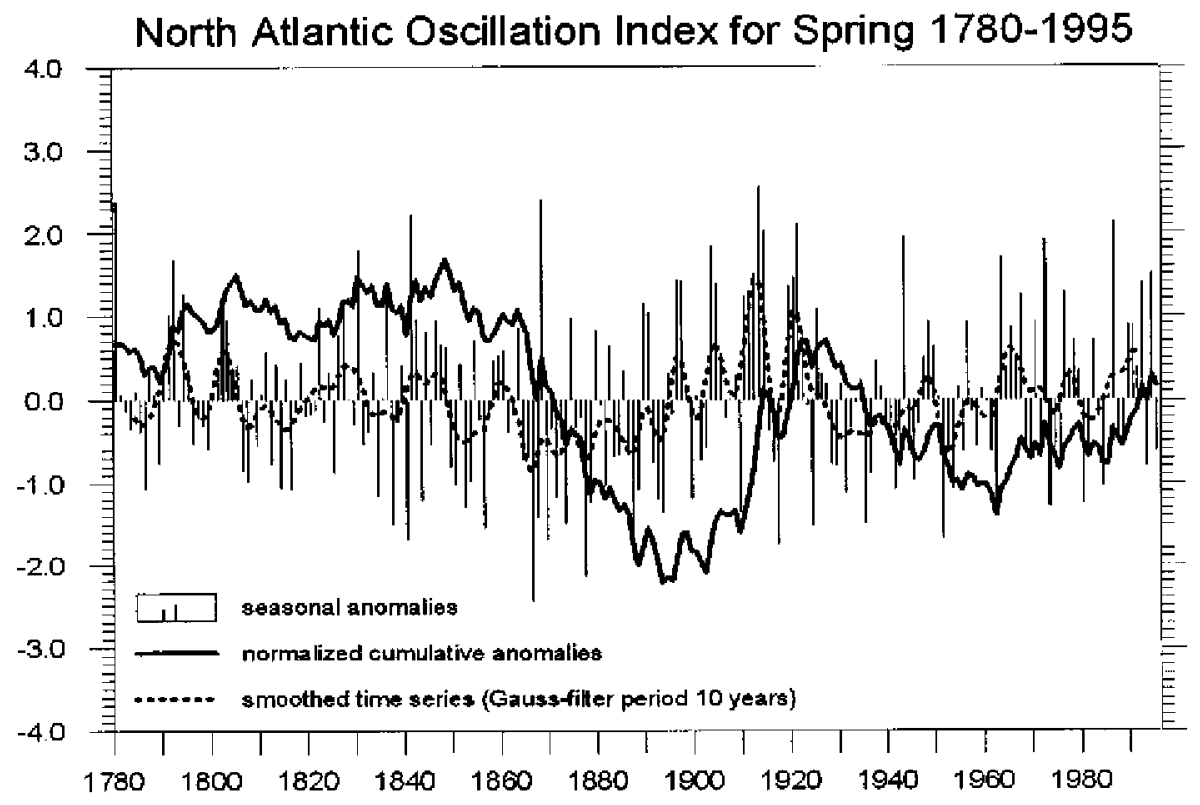

Central European Zonal Index for Spring 1780-1995

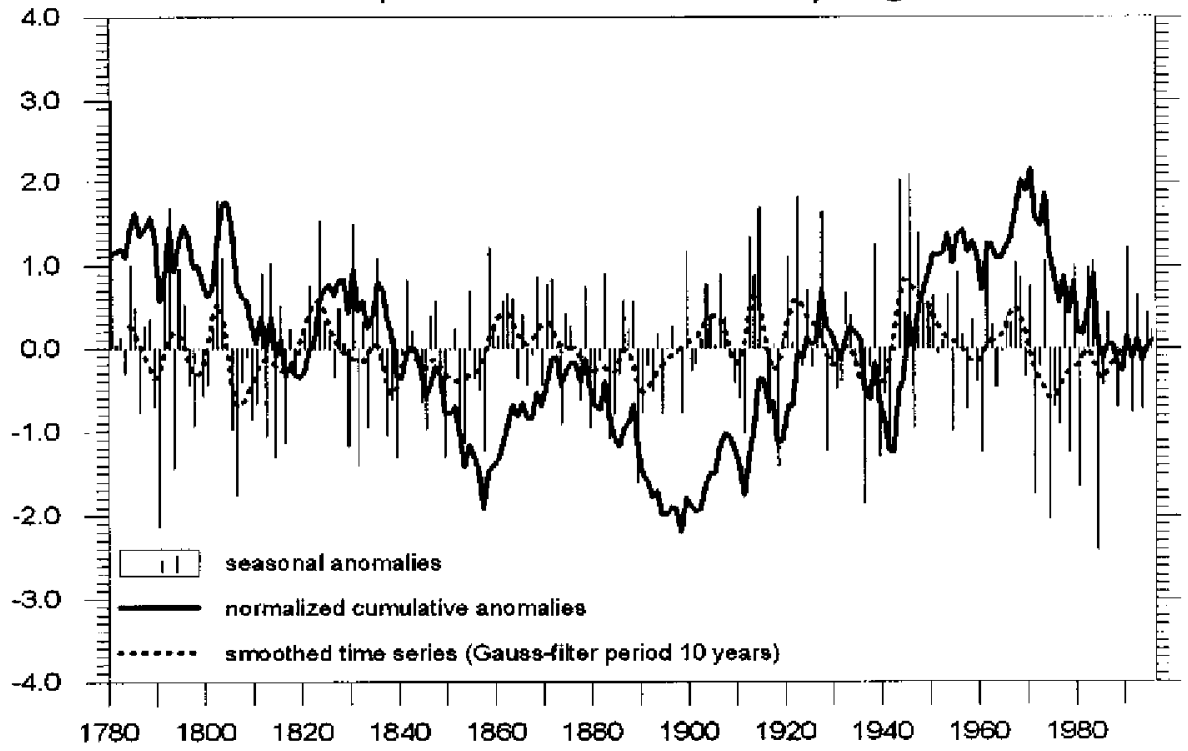

Figure 3. (Continued) 

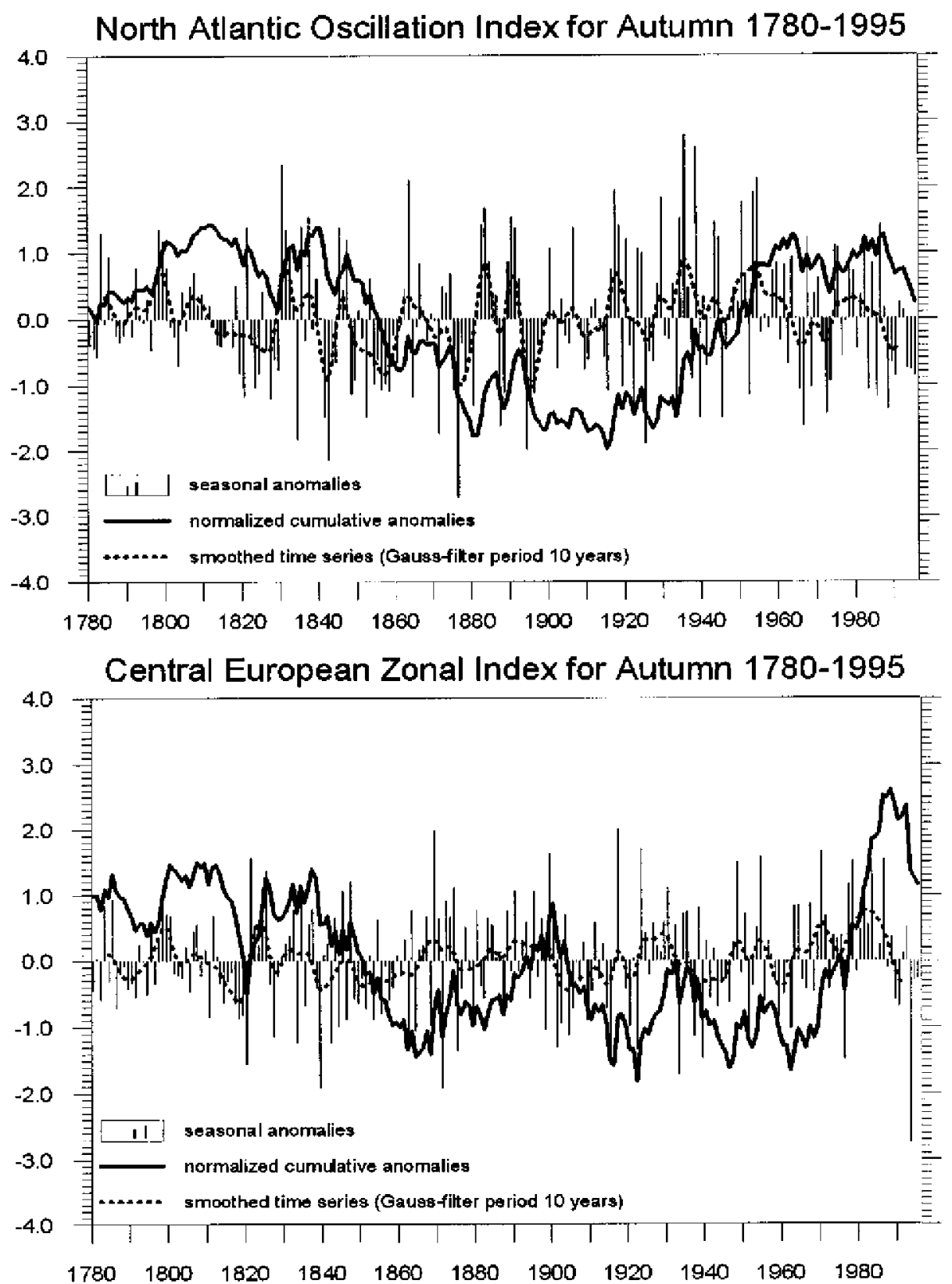

Figure 3. (Continued) 
Concerning the extent to which the circulation indices have increased during the most recent period in winter it should be stressed that only for the very short period since 1989 the indices based on gridded data are significantly higher than in the earlier periods with positive seasonal anomalies. Since this short period has not continued during the last years (Jones et al., 1997) it cannot define an extraordinary interval in terms of major periods in cumulative anomalies (Fig. 3).

For the transitional seasons we get declining tendencies in cumulative anomalies at some time during the nineteenth century, i.e. periods of variable length with prevailingly negative seasonal anomalies, most distinctly for NAOI in spring during the second half of the nineteenth century, more oscillatory for CEZI in spring, and generally less marked during autumn. Opposite developments (accumulating positive seasonal anomalies) within the twentieth century again are differing in detail: concentrated to the first decades for NAOI in spring, more elongated but oscillatory for CEZI in spring, lasting until the 1960s for NAOI in autumn, and just starting at this time for CEZI in autumn.

As a main result, however, the hundred years preceding the time when previously available data sets are starting, indicate modified conditions in atmospheric circulation compared to the modern century, affecting all seasons in a different way. This might be important for the transition from the "Little Ice Age" to the subsequent period as will be discussed in chapter 5 .

\subsection{RUNNING CORRELATIONS WITH TEMPERATURE}

Comparisons between different zonal indices in the last chapter have indicated that there might be major instationarities in circulation-climate relationships. This is verified by running correlations between zonal indices and various European temperature time series.

First we look at the overall zonal index, ZI, and its running correlations with temperature for all months of the year (Fig. 4). As a distinct result we get no persistence over time of correlation coefficients within one and the same class, for all included regions (Central England, Stockholm, southwestern and northeastern Central Europe) and at every time during the year (note that each class of coefficients has a range of values of 0.2 ). The longest interval with variations confined within one class occurs for Stockholm during February extending from the 1830s to the 1940s. But even this example includes differences in correlation coefficients of up to more than 0.6 considering the whole period from 1780 to 1995 . Remarkably, even during winter, coefficients may drop to low values. During the decades around 1880 there is a widespread shift of the seasonal correlation structure: the high correlations during winter persist during spring, and the usually low correlations during summer are replaced by higher ones (resembling spring conditions) during these decades. 


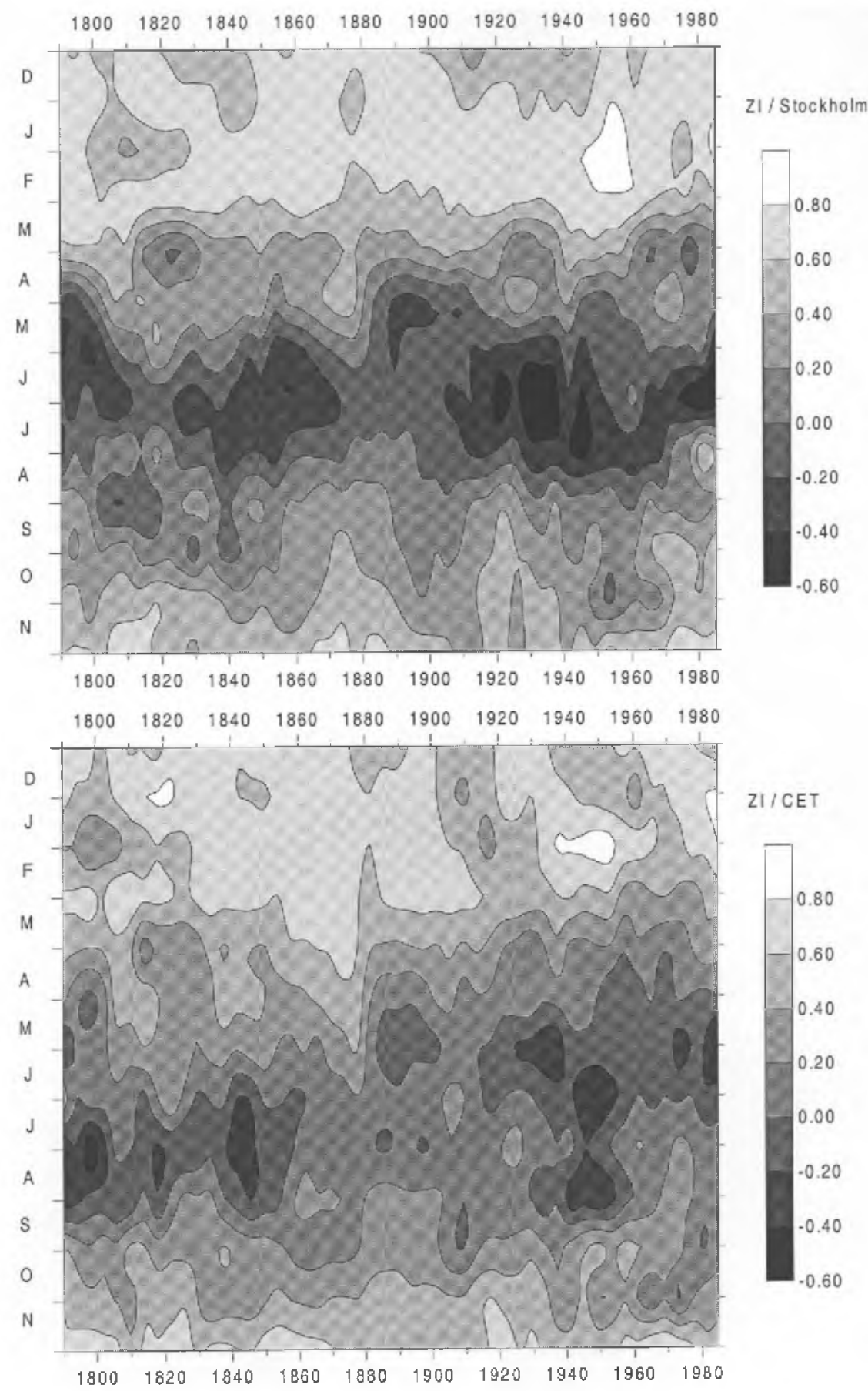

Figure 4. Isopleth diagrams showing the evolution over time of the annual course of running correlations between the overall zonal index (ZI) and regional temperature time series (Stockholm; Central England-CET). The contours are smoothed to show decadal scale variations. 

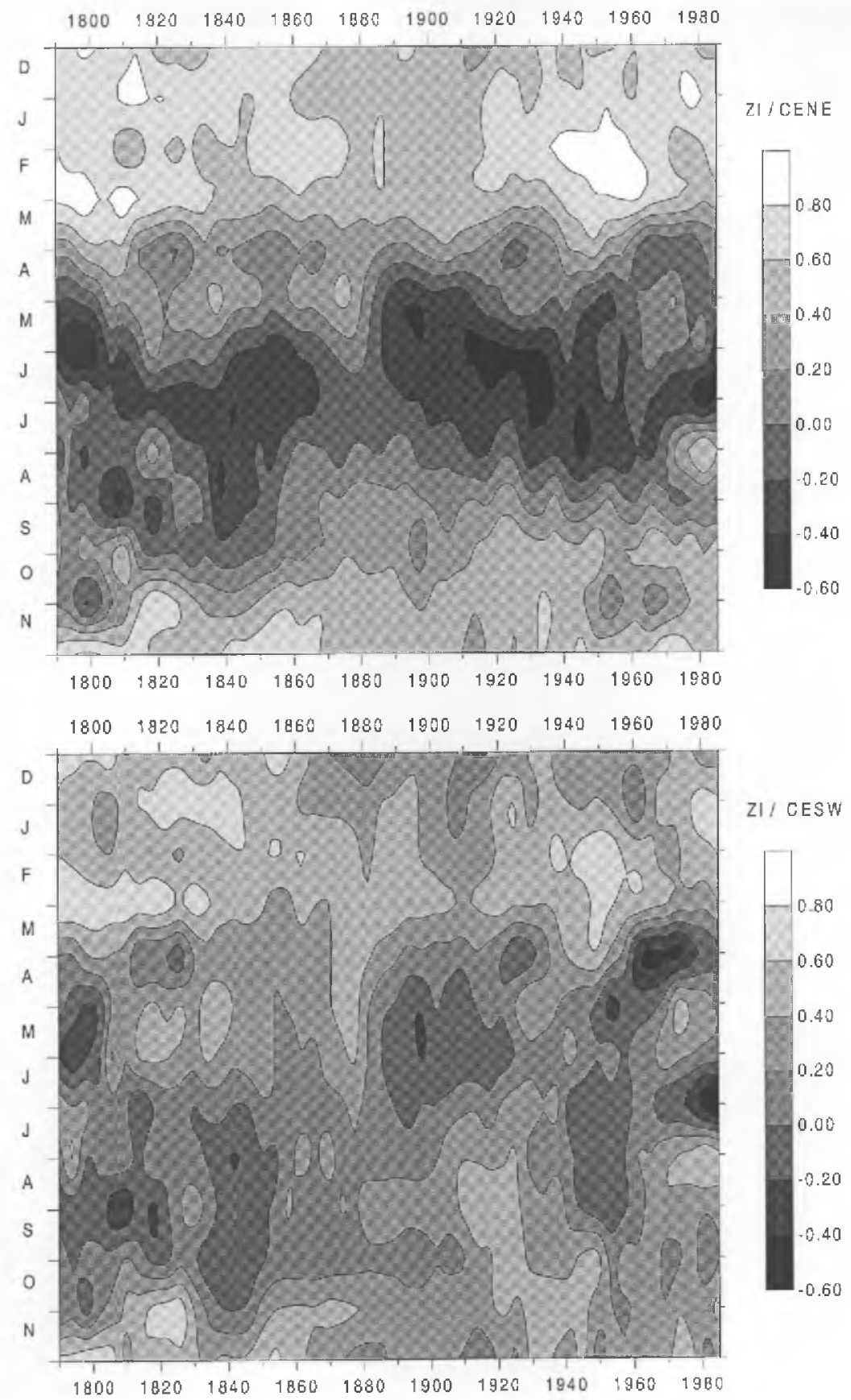

Figure 4. (Cont.) ZI - overall zonal index; CENE - temperature of Central European Region NE; CESW - temperature of Central European Region SW. 
To resolve variations in circulation-temperature relationships explicitly (i.e. without any classification) Fig. 5 gives selected time series of running correlation coefficients related to the regionally defined indices NAOI and CEZI. Examples are confined to the winter season and to two particular cases from summertime. Due to the effect that seasonal integration may differ between circulation and temperature indices their correlation coefficients sometimes may vary differently comparing monthly and seasonal resolution of the same selected case.

Looking at the four cases relating the temperature time series described above to the NAOI series for winter (Fig. 5) we get considerable ranges of correlation coefficients varying around the mean values for the whole period 1780-1995 $(0.57$, $0.64,0.57,0.58$ with monthly resolution and $0.67,0.66,0.63,0.58$ with seasonal resolution for Stockholm, Central England, Central European regions NE and SW, respectively). Particularly important is the distinct result of profoundly lower correlations at the beginning of the twentieth century compared with both recent as well as former times during the last two centuries. The drop in correlation coefficients around the turn from the nineteenth to the twentieth centuries is most pronounced for Central England based on seasonal resolution. For southwestern Central Europe the decline in correlation levels already set in from the $1820 \mathrm{~s}$ onwards whereas the northern regions (NECentral Europe, Stockholm) experienced a first period of lower correlations during the first half of the nineteenth century before recovered values from the second half of the century again dropped to the lower levels mentioned above. With monthly resolution the amplitudes of variation are considerably smaller; thus, declines in correlation coefficients do not reach the lower limit for $95 \%$ statistical significance (approximately at $r=0.25$ ), but still we get major variations reaching absolute differences in correlation coefficients of more than 0.5 for southwestern Central Europe. This region as well as Central England furthermore attain a second minimum around 1950 intervening within the modern period of higher correlation levels.

Correlations with CEZI only are given for the Central European regions since the other regions are located to the west (Central England) or in the northern periphery (Stockholm). For the whole period 1780-1995 correlation coefficients based on monthly and seasonally resolved data are 0.76 and 0.80 for the NE region and 0.66 and 0.67 for the SW region, respectively, thus reaching higher levels than the corresponding cases with NAOI mentioned above. But looking at the running correlations (Fig. 5) we get again distinctly varying values with lowest correlation coefficients at the beginning of the twentieth century. In this case, however, they do not result from a continuous decline because the $1890 \mathrm{~s}$ - in contrast to the correlations with NAOI - appear as an intervening period of recovered values. In general, correlations with CEZI are varying more oscillatory,

Figure 5. (Next two pages) Running correlations between circulation indices (NAOI, CEZI) and regional temperature time series (Stockholm, Central England, Central European Regions NE and SW). See text for calculation modes of running monthly and seasonal correlations. 

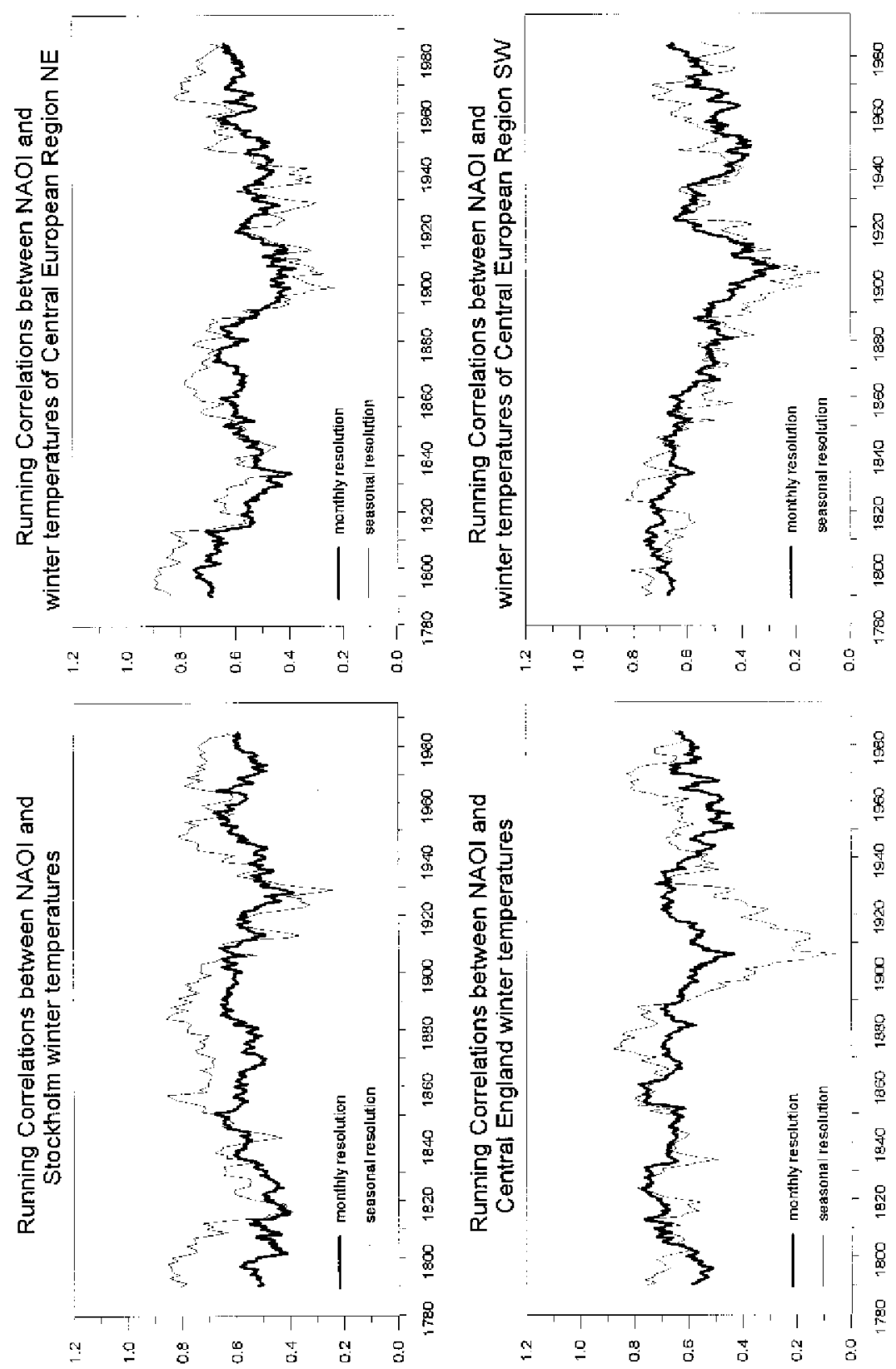

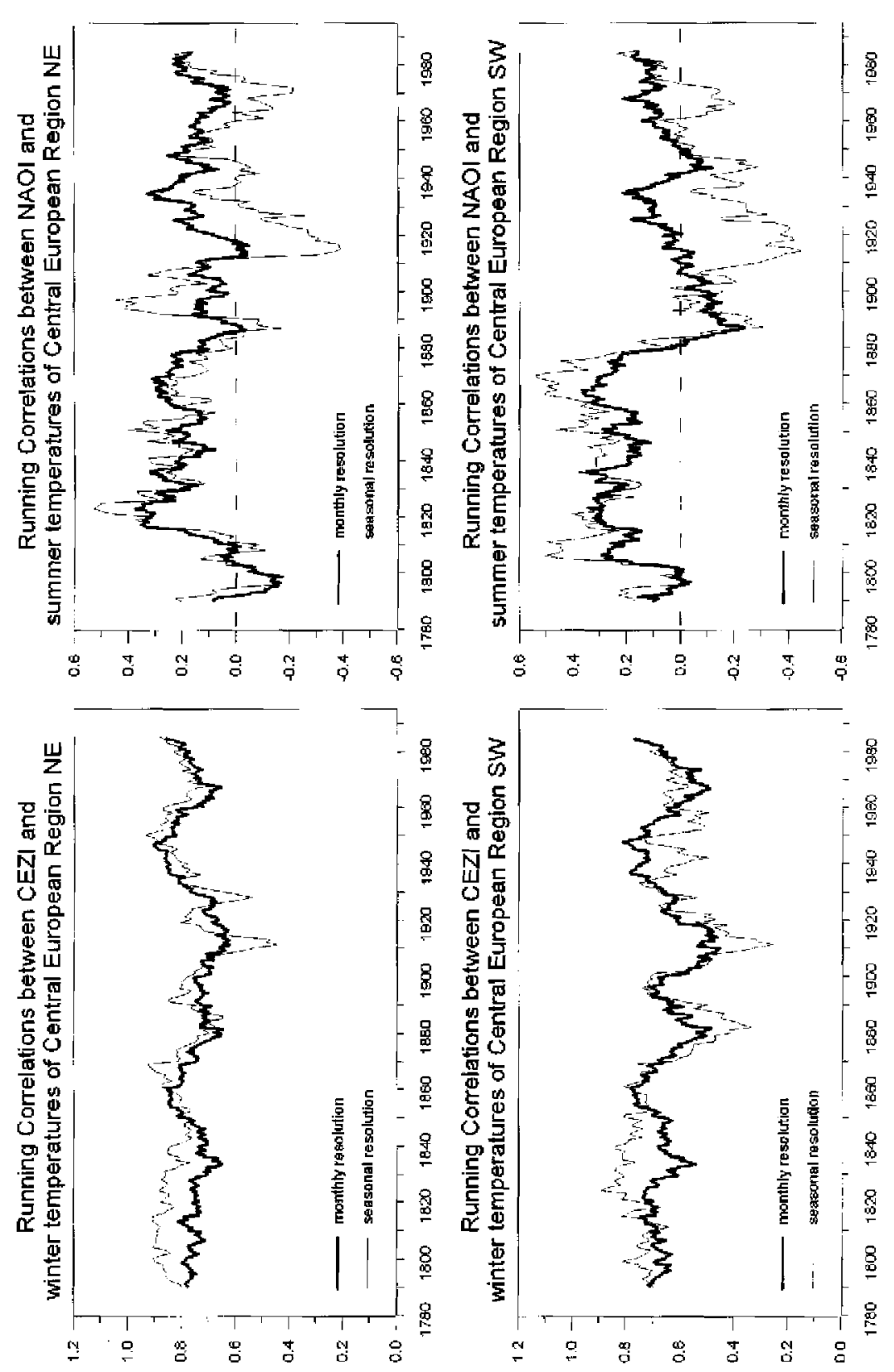
especially for monthly resolution with several minima during the $1830 \mathrm{~s}, 1880 \mathrm{~s}$, $1910 \mathrm{~s}$ and $1960 \mathrm{~s}$ and alternating maxima around 1860 , during the $1890 \mathrm{~s}, 1940 \mathrm{~s}$ and 1980s.

Correlations for the summer season generally are weaker and often statistically insignificant. Therefore only two examples implying major variations over time are included in Fig. 5. It is particularly noteworthy that, in contrast to the modern conditions with low correlation coefficients between NAOI and central European temperature, this relationship was positive for the greater part of the nineteenth century (95\% statistical significance is reached with $r>0.25$ on the monthly scale and $r>0.44$ on the seasonal scale). This was partly due to zonal ridges of high pressure (i.e. high values in NAOI and central European summer temperatures) which were more important for the atmospheric circulation in the former period than during the recent century (Jacobeit et al,, 1998). The 'continental' index CEZI actually gives negative correlations with central European summer temperatures (at least for the northern region) but this relationship dropped to insignificant values during the first decades of the analyzed period and between 1870 and 1890 . Thus, circulation-climate relationships do not necessarily remain stationary if periods of investigation are extended further into the historical past.

\section{Discussion}

The mass reduction of many European glaciers since the mid-nineteenth century, often referred to as the end of the "Little Ice Age" (e.g. Flohn, 1993), should be reflected in some atmospheric circulation changes since there exists a general coupling between circulation and the glacier mass balance (Pohjola and Rogers, 1997). For recent boundary conditions, for example, the net mass balance in the European Alps is favoured by westerlies, troughs and depressions increasing accumulation in winter, but reducing ablation in summer (Fitzharris, 1998). Of course, these conditions may not occur simultaneously in winter and summer, and particular large-scale weather types during spring and autumn also influence the mass balance of glaciers as already shown by Hoinkes (1968). Furthermore, the response of indi-vidual glaciers is even more complicated and does not only depend on variables linked to atmospheric circulation (temperature, precipitation and cloudiness) but also on glacier geometry and location (Oerlemans, 1994; Oerlemans et al., 1998) together with topography, altitude and response time (Kuhn et al., 1985).

Based upon this background no immediate relationships between glacier mass balance and zonal circulation indices can be inferred. However, zonal indices are indicating particular states of the atmosphere which might be differing in frequency between different climatic periods. Thus, without a direct link to glacier behaviour, the "Little Ice Age" and the subsequent period of warming might be distinguished by different prevailing circulation modes indicated in the time series of cumulative 
anomalies of an appropriate zonal circulation index. In fact, the NAOI calculations (Fig. 3) based on gridded SLP reconstructed back to 1780 do reveal distinct circulation changes within the nineteenth century: during winter an extended accumulation of negative anomalies until the 1850 s was replaced by prevailing positive anomalies afterwards, in contrast to that, positive anomalies in NAOI accumulated during summer until the 1870 s subsequently changing to an opposite evolution. Thus, the different turning points in cumulative anomalies indicate, in terms of circulation modes, the transition period between the "Little Ice Age" and the following warming period, a transition that started in winter during the $1850 \mathrm{~s}$ and concluded in summer some 20 years later.

No distinct preference for negative anomalies, however, is indicated for the Central European Zonal Index (CEZI) during the historical winter seasons until the 1850 s - thus it cannot be excluded that the prevailing low-index mode in NAOI during this time might be due to the lower performance in SLP grid reconstruction for marginal areas, especially during the first decades since 1780 . This uncertainty in the early part of the reconstruction highlights the need to elaborate further high quality station time-series covering the earliest part of the period, particularly stations in the periphery of the North-Atlantic-European region. On the other hand, low values in NAOI during winter still are indicated after the 1820 s when station pressure time series from Reykjavik and Gibraltar have entered the network for SLP grid reconstruction (Jones et al., 1999). Furthermore, marked differences between NAOI and CEZI also do occur for later periods with enhanced data bases, e.g. the time-lagging turning points to prevailing negative anomalies in winter during the twentieth century or the period with cumulating negative anomalies in NAOI during summer around the turn from the nineteenth to the twentieth centuries which is com-pletely missing within the corresponding CEZI series. Due to different circulation patterns different modes in NAOI and CEZI may in fact be linked with each other, e.g. high-index conditions above the Atlantic with continental blocking patterns decreasing CEZI values to intermediate or even negative levels. Thus, the correlation coefficient between NAOI and CEZI being 0.68 during winter for the whole period 1780-1995 sometimes drops to significantly lower values, e.g. around 0.2 for running 21 -year periods at the beginning of the twentieth century when lower values in the circulation-temperature relationships (see below) also hint at intervening changes in circulation patterns. For the end of the "Little Ice Age" we conclude in general that the NAOI most probably preferred below-average values in winter linked with greater variability in CEZI including patterns of mixed circulation type (transitional between zonal and meridional types). For the summer season both indices preferred above-average values even some decades beyond the mid-nineteenth century thus indicating an extended period of transition between the different seasonal circulation modes characterizing the "Little Ice Age" and the subsequent climatic period in Europe.

The second part of the investigation focussed on circulation-temperature relationships. Considering the seasonal cycle in the overall zonal index (ZI)-temperatu- 
re correlations (Fig. 4) we get a distinct climatic zonation: in the more continental regions of central Sweden (represented by Stockholm) and northeastern Central Europe (CENE, see Fig. 1) there is a large seasonal cycle in the correlations (positive during winter and negative during summer). In the maritime climate of Central England this seasonality is less distinct, even though there is an indication of an increased seasonal cycle after about 1920. The seasonal ZI-temperature cycle of southwestern Central Europe (CESW) has similar characteristics as the maritime Central England region.

This climatic zonation is due to particular geographical circumstances. Thus, during situations with influx of continental air from the east, Central England mostly retains relatively maritime conditions - apart from distinct anomaly periods like the Late Maunder Minimum at the end of the seventeenth century - because of the North Sea. The much smaller Baltic Sea cannot produce a similar transformation of the air mass thus rendering Sweden a more continental climate. This is particularly pronounced during winters when the Baltic sea-ice is extended to the south. These geographical circumstances produce a ZI-temperature correlation pattern that is similar for Stockholm and the northeastern Central European region (CENE). The southwestern Central European region (CESW), however, is more similar to Central England than to the Central European northeasterly region despite the fact that there is no large water body to the east of this region that would modify the continental air mass.

Further investigations have identified significant instationarities in correlations between circulation indices and temperature time series for both monthly and seasonal resolution of the corresponding samples from 1780 onwards (Fig. 5). Similar results (not shown here) are obtained for spring and autumn and for various timescales in running correlations (e.g. for three or four instead of two decades as moving time windows). These instationarities point to the fact that both positive and negative modes of circulation index variations are including different circulation patterns with quite different effects on Central European climate: for example, positive modes of the NAO are not only related to westerly flow types with aboveaverage winter temperatures in Central Europe, but sometimes also to mixed circulation types with Central European high pressure systems leading to below-average winter temperatures due to long-wave radiation losses. On the other hand, even weak zonal flow above the North Atlantic (i.e. negative mode of the NAO) sometimes is related to persistent westerly advection towards Central Europe with quite warm conditions during winter. Schmutz and Wanner (1998) also give examples of circulation patterns with unexpected regional temperatures in terms of different modes of the NAO. Thus, if changes of circulation patterns within a particular index mode do occur, correlations between this circulation index and regional temperatures may not remain persistent over time - the NAOI being an indicator of the state of the climate system in the North Atlantic area must not be used as a stable indicator for surrounding regional climates like in Central Europe as well as these climates are not qualified as proxy indicators for North Atlantic circulation 
modes on multi-decadal time-scales. In general, the European climate is more complex than can be captured by a simple circulation index like the NAOI.

Major shifts in circulation-temperature relationships have been identified for both winter and summer conditions. During summer changes occurred between the nineteenth and the twentieth centuries from positive to near-zero correlations between NAOI and southwestern Central European temperatures, from near-zero to negative correlations between CEZI and northeastern Central European temperatures. This might be due, at least in part, to the above-mentioned decrease in zonal high pressure ridges for summer. During winter the varying levels of correlations between circulation indices and European temperatures reveal a major event common to all particular cases under consideration: the marked decline in correlations around the turn from the nineteenth to the twentieth centuries leading to significantly lower values in the circulation-temperature relationships at the beginning of this century. Additionally, the northern regions (NE Central Europe, Stockholm) experienced a first period of lower correlations with NAOI during the first half of the nineteenth century, the southwestern regions (Central England, SW Central Europe) a second minimum period around 1950. Most important seems to be the former period around the last turn of centuries, since similar declines in correlations for this time have been reported from other regions, too, e.g. from the eastern Alpine region (Böhm et al., 1998) or from the Greenland area based on oxygen isotope data from ice cores (Steig and Barlow, 1998). Especially the 1890 s are particularly striking in terms of circulation dynamics since running correlations with temperature develop differently around this time with increasing values (for an intervening period) in relation to CEZI while correlations with NAOI already decline towards their minimum level.

In order to understand these instationarities in circulation-climate relationships further investigations have to be directed towards the question whether there are significant redistributions among basic circulation patterns within particular index modes between different periods of high and of low correlations with regional European temperatures. Selecting periods of high, of low, and of rapidly changing correlations according to Fig. 5 will allow to investigate whether major NAO modes are dominated by different circulation patterns during these selected periods. Since this kind of variability is operating on decadal to centennial time scales periods covered by objectively reconstructed SLP data are required extending as far as possible into the historical past including sections of the "Little Ice Age" which additionally offer an extended range of natural variability in climate, circulation and their relationships. Thus, historical and dynamic climatology are linked by reconstructing past climates and simultaneously investigating atmospheric circulations over periods of several centuries thereby ensuring results that are valid not only for a few decades with limited range in variability. 


\section{Acknowledgements}

This work has been supported by the European Commission under grant ENV4CT95-0129, coordinated by Trevor Davies and Phil Jones (Climatic Research Unit, University of East Anglia, Norwich, UK). We thank the two reviewers, Rudolf Brazdíl and Heinz Wanner, for suggesting useful improvements to the paper.

\section{References}

Barnston, A.G. and Livezey, R.E.: 1987, 'Classification, seasonality and persistence of lowfrequency atmospheric cireulation patterns', Mon. Wea. Rev. 115, 1083-1126.

Bārring, L., Jönsson, P., Achberger, C., Ekström, M. and Alexandersson, H.: 1999, 'The Lund record of meteorological instrument observations: reconstruction of monthly sea-level pressure 1780-1997', Int. J. Climatol. 19, 1427-1443.

Beck, C.: 2000, 'Zirkulationsdynamische Variabilität im Bereich Nordatlantik-Europa seit 1780', Wirzburger Geographische Arbeiten (in press).

Böhm, R., Auer, I., Hagen, M. and Schöner, W.: 1998, 'Is there a NAO-signal in Alpine climate time series?', Abstracts of The Second International Climate and History Conference. Norwich $1998,36$.

Corti, S., Molteni, F. and Palmer, T.N.: 1999, 'Signature of recent climate change in frequencies of natural atmospheric circulation regimes', Nature 398, 799-802.

Dickson, R., Lazjer, J., Meincke, J. Rhines, P. and Swift, J.: 1996, 'Long-term coordinated changes in the convective activity of the North Atlantic', Progr. Oceanogr. 38, 241-295.

Fitzharris, B.: 1998, 'A synoptic climatology of glacier mass balance for the European Alps', in Clinate and Environmental Change, International Geogtaphical Union, Commission on Climatology, Evora 1998, 141-142.

Flohn, H.: 1993, 'Climatic evolution during the last millenium: what can we learn from it?', in Eddy, J.A. and Oeschger, H. (eds.), Global Changes in the Perspective of the Past, Wiley \& Sons, Chichester et al., pp. 295-316.

Hoinkes, H.C.: 1968, 'Glacier variations and weather', J. Glaciol. 7, 3-19.

Hurrell, J.W.: 1995, 'Decadal trends in the North Atlantic Oscilation: regional temperatures and precipitation', Science 269, 676-679.

Hurrell, J.W.: 1996, 'Influence of variations in extratropical wintertime teleconnections on Northern Hemisphere temperature', Geophys. Res. Let. 23, 665-668.

Hurrell, J.W. and van Loon, H.: 1997, 'Decadal variations in climate associated with the North Atlantic Oscillation', Clim. Change 36, 301-326.

Jacobeit, J., Beck, C. and Philipp, A.: 1998, 'Annual to decadal variability in climate in Europeobjectives and results of the German contribution to the European climate research project ADVICE', Würburger Geographische Manuskripte 43, 163 pp.

Jones, P.D., Jonsson, T. and Wheeler, D.: 1997, 'Extension of the North Atlantic Oscillation using early instrumental pressure observations from Gibraltar and south-west Iceland', Int. J. Climatol. 17, 1433-1450.

Jones, P. D., Davies, T. D., Lister, D. H., Slonosky, V., Jonsson, T., Bärring, L., Jönsson, P., Maheras, P., Kolyva-Machera, F., Barriendos, M., Martin-Vide, J., Alcoforado, M. J., Wanner, H., Pfister, C., Schuepbach, E., Kaas, E., Schmith, T., Jacobeit, J. and Beck, C.: 1999: 'Monthly mean pressure reconstructions for Europe for the 1780-1995 period', Int. J. Clinatol $19,347-364$. 
Jönsson, P. and Bärring, L.: 1994, 'Zonal index variations, 1899-1992, and links to air temperature in southern Scandinavia', Geogr. Ann. 76A, 207-219.

Kuhn, M., Markl, G., Kaser, G., Nickus, U., Obleitner, F. and Schneider, H.: 1985, 'Fluctuations of climate and mass balance: different responses of two adjacent glaciers', Z. Gletscherkunde u. Glazialgeologie 21, 409-416.

Lamb, P.J. and Peppler, R.A.: 1987, 'North Atlantic Oscillation: Concept and application', Bull. Am. Met. Soc. 68, 1218-1225.

Mächel, H., Kapala, A. and Flohn, H.: 1998, 'Behaviour of the centres of action above the Atlantic since 1881. Part I: Characteristics of seasonal and interannual variability', Int. J. Climatol. 18, $1-22$.

Malberg, H. and Bökens, G.: 1997, 'Die Winter- und Sommertemperaturen in Berlin seit 1929 und ihr Zusammenhang mit der Nordatlantischen Oszillation (NAO)', Meseorol. Z. N.F. 6, 230-234.

Manley G.: 1974, 'Central England Temperatures: monthly means 1659 to 1973 ', Quart. J. Roy. Met. Soc. 100, 389-405.

Moberg, A. and Bergström, H.: 1997, 'Homogenization of Swedish temperature data. Part III: The temperature records from Uppsala and Stockholm', Int. J. Climatol. 17, 667-699.

Moses, T., Kiladis, G. N., Diaz, H. F. and Barry, R. G.: 1987, 'Characteristics and frequency of reversals in mean sea level pressure in the North Atlantic sector and their relationship to long-term temperature trends', J. Climatol. 7, 12-30.

Oerlemans, J., Anderson, B., Hubbard, A., Huybrechts, Ph., Jóhannesson, T., Knap, W. H., Schmeits, M., Stroeven, A. P., van de Wal, R. S. W., Wallinga, J. and Zou, Z.: 1998, 'Modelling the response of glaciers to climate warming', Clim. Dyn. 14, 267-274.

Oerlemans, J.: 1994, 'Quantifying global warming from the retreat of glaciers', Science 264, 243-245.

Parker D. E., Legg T. P. and Folland C. K.: 1992, 'A new daily Central England Temperature series, 1772-1991', Int. J. Climatol. 12, 317-42.

Pohjola, V. A. and Rogers, J. C.: 1997; 'Coupling between the atmospheric circulation and extremes of the mass balance of Storglaciären, northern Scandinavia', Ann. Glaciol. 24, 229-233.

Rodríguez, R., et al: (subm.), 'The long pressure series of Barcelona (Spain), daily reconstruction and monthly homogenization', Int. J. Climatol. (submitted).

Rogers, J.C.: 1984, 'The association between the North Atlantic Oscillation and the Southern Oscillation in the Northern Hemisphere', Mon. Wea. Rev. 112, 1999-2015.

Rogers, J. C.: 1985, 'Atmospheric circulation changes associated with the warming over the northern North Atlantic in the 1920s', J. Clim. Appl. Met. 24, 1303-1310.

Rogers, J.C.: 1990, 'Patterns of low-frequency monthly sea-level pressure variability (1899-1986) and associated wave cyclone frequencies', J. Clim. 3, 1364-1379.

Schmutz, C. and Wanner, H.: 1998, 'Low frequency variability of atmospheric circulation over Europe between 1785 and 1994', Erdkunde 52, 81-94.

Schönwiese, C.-D. and Rapp, J.: 1997, 'Climate trend atlas of Europe, based on observations 1891 1990', Kluwer, Dordrecht.

Steig, E. and Barlow, L.: 1998, 'High-resolution proxy climate data from ice cores - an overview', Abstracts of The Second International Climate and History Conference, Norwich 1998, 29.

Steinrücke, J.: 1999, 'Changes in the Northern Hemispheric Zonal Circulation and their relationship to precipitation frequencies in Europe', Bochumer Geographische Arbeiten 65, $135 \mathrm{pp}$.

Wanner, H., Gyalistras, D., Luterbacher, J., Rickli, R., Salvisberg, E. and Schmutz, C.: 2000, 'Klimawandel im Schweizer Alpenraum', Vdf Hochschulverlag AG, Zürich.

World Climate Disc: 1992, 'Global Climate Change Data', Climatic Research Unit, University of East Anglia. 